\title{
A conventional polymerase chain reaction-based method for the diagnosis of human schistosomiasis in stool samples from individuals in a low-endemicity area
}

\author{
Teiliane Rodrigues Carneiro', Regina Helena Saramago Peralta' ${ }^{2}$, Marta Cristhiany Cunha Pinheiro ${ }^{1,3}$, \\ Sara Menezes de Oliveira', José Mauro Peralta ${ }^{4}$, Fernando Schemelzer Moraes Bezerra ${ }^{1,3,5 /+}$ \\ ${ }^{1}$ Departamento de Patologia e Medicina Legal ${ }^{3}$ Departamento de Análises Clínicas e Toxicológica \\ 5epartamento de Saúde Coletiva, Universidade Federal do Ceará, Fortaleza, CE, Brasil ${ }^{2}$ Departamento de Patologia, \\ Universidade Federal Fluminense, Niterói, RJ, Brasil ${ }^{4}$ Departamento de Imunologia, Instituto de Microbiologia Paulo de Goes, \\ Universidade Federal do Rio de Janeiro, Rio de Janeiro, RJ, Brasil
}

The aim of this study was to evaluate the efficacy of a polymerase chain reaction (PCR)-based method to detect Schistosoma mansoni DNA in stool samples from individuals living in a low-endemicity area in Brazil. Of the 125 initial stool samples, 80 were ELISA reactive and eggs were identified in 19 of the samples by parasitological examination. For the PCR evaluations, 56 stool samples were selected and divided into five groups. Groups I-IV were scored negative for $\mathrm{S}$. mansoni eggs by parasitological examination. Groups I and II were ELISA reactive, whereas Groups III and IV were ELISA nonreactive. Groups II and III were positive for other intestinal parasites. PCR testing scored eight samples as positive from these four groups. Group V represented the $\mathrm{S}$. mansoni-positive group and it included ELISA-reactive samples that were scored positive for S. mansoni by one or more parasitological examinations (6/19 were positive by Kato-Katz method, 9/17 by saline gradient and 10/13 by Helmintex ${ }^{\circledR}$ ). PCR scored 13 of these 19 samples as positive for S. mansoni. We conclude that while none of these methods yielded $100 \%$ sensitivity, a combination of techniques should be effective for improving the detection of $\mathrm{S}$. mansoni infection in low-endemicity areas.

Key words: Schistosoma mansoni - PCR - Kato-Katz - ELISA - saline gradient - Helmintex ${ }^{\circledR}$

Although considered to be among the "neglected tropical diseases" of the world (Molyneux et al. 2005, Hotez et al. 2006), schistosomiasis remains one of the most common parasitic diseases throughout the tropics and subtropics and is a major public health problem in these areas (van der Werf et al. 2003, Steinmann et al. 2006). Laboratory diagnoses are primarily based on the detection of parasite eggs in the stool using the KatoKatz (KK) method (Katz et al. 1972). This approach is low-cost and easy to perform and provides information on both the prevalence and intensity of the infection. However, a well-known limitation of parasitological (i.e., morphological) examinations is a lack of sensitivity, particularly in low-endemicity areas and in individuals with low parasite loads (Utzinger et al. 2001, Gonçalves et al. 2006, Enk et al. 2008). To overcome this limitation, it is often necessary to analyse larger stool quantities (Bergquist et al. 2009) or to include new diagnostic methods (Cavalcanti et al. 2013).

doi: 10.1590/0074-0276130202

Financial support: CAPES, CNPq, FAPERJ

+ Corresponding author: bezerra@ufc.br

Received 12 April 2013

Accepted 7 October 2013
Other parasitological methods for the detection of schistosomiasis have been described, such as Helmintex ${ }^{\circledR}$ or saline gradient methods (Teixeira et al. 2007, Coelho et al. 2009). In the Helmintex ${ }^{\circledR}$ method, Schistosoma mansoni eggs are concentrated using paramagnetic beads to improve microscopic detection. Somewhat similarly, the saline gradient method is a simple procedure that uses a salt gradient to purify eggs to allow for easier detection with microscopic examination. Serological antibody detection assays, including ELISAs with a variety of antigen preparations (de Noya et al. 2007), have also been used as tools to diagnose schistosomiasis. Although these methods are low-cost, reproducible, objective, rapid and potentially automatable (de Noya et al. 2006), they are poor at distinguishing between past and present infections.

The state of Ceará (CE) in northeastern Brazil has been characterised as a low-prevalence area by the Schistosomiasis Control Program. A study conducted by our group in Planalto do Cajueiro, Maranguape-CE found a disease prevalence of $16 \%$ (40 positive individuals out of 250 evaluated) in 2010 using the KK diagnostic method (1 sample, 3 slides). Due to the appreciated lack of sensitivity of this method, we conducted another study in the region using three other parasitological techniques and one serological antibody detection method to better determine the prevalence of this disease. This study demonstrated that the Helmintex ${ }^{\circledR}$ technique was more effective than both the KK and saline gradient methods, although certain cases were missed by all three assays (Pinheiro et al. 2012). 
Evaluation of circulating anodic antigen (CAA) and cathodic current antigen (CCA) levels in the serum or urine of infected individuals using ELISA has been proposed as an alternative technique to overcome the problems inherent to antibody detection (Deelder et al. 1989, van Lieshout et al. 1993, van Etten et al. 1994). Studies suggest that the diagnosis of $S$. mansoni through the detection of CCA in urine using reagent strips can provide information on the prevalence of schistosomiasis in high-endemicity areas. Nevertheless, it is of practical importance to assess the efficacy of any new technique for schistosomiasis diagnosis, especially in low-endemicity areas, before applying these techniques for routine diagnostic or epidemiological purposes (Legesse \& Erko 2007).

Recent studies have shown that indirect diagnostic tests (e.g., point-of-care circulating cathodic antigen) are valuable alternatives to direct parasitological methods for the diagnosis of $S$. mansoni infections (Coulibaly et al. 2011, Stothard et al.2011). Although schistosome antigens, such as CCA and CAA, can be detected in the serum and urine of infected individuals (Coulibaly et al. 2013), the sensitivity and specificity of these assays have not been determined in low-endemicity areas (Colley et al. 2013).

Techniques for identifying circulating $S$. mansoni DNA have been widely used and such methods have demonstrated that it is possible to detect infections as early as one day after parasite exposure (Kato-Hayashi et al. 2010, Sulbaran et al. 2010, Gentile et al. 2011). PCR-based diagnoses have been shown to be highly sensitive and specific and should therefore be considered as alternative methods for the diagnosis of $S$. mansoni infections. Such methods have already been used to detect $S$. mansoni DNA in samples of stool (Pontes et al. 2002, Espírito-Santo et al. 2012), blood serum (ten Hove et al. 2008, Haggag \& Abdullah 2011), blood plasma (Wichmann et al. 2009) and urine (Sandoval et al. 2006, Enk et al. 2012). Real-time polymerase chain reaction (PCR) has also been used to diagnose schistosomiasis (ten Hove et al. 2008) and this technique can be used a potential therapeutic cure control method, as has been demonstrated in animal models of experimental infection (Gentile et al. 2011).

In this study, we evaluated the efficacy of a conventional PCR-based method for the diagnosis of human schistosomiasis in individuals from a low-endemicity area in CE.

\section{SUBJECTS, MATERIALS AND METHODS}

Study population - The Planalto do Cajueiro is a small community composed of approximately 903 inhabitants distributed across five urban blocks, according to a survey conducted by the city hall. The area is surrounded by two streams containing Biomphalaria straminea, the intermediate host of $S$. mansoni. The main source of income for the residents of this town is subsistence agriculture, with the addition of some textile and footwear manufacturing. Due to the poor infrastructure and sanitation, this population is at risk for the transmission of a number of diseases, including schistosomiasis, leishmaniasis, dengue and others.
In total, 125 stool samples were collected from individuals living in Planalto do Cajueiro, Maranguape, a low-endemicity area for schistosomiasis, and were analysed using the parasitological KK - Helm-Test ${ }^{\circledR}$ (hereafter KK) and ELISA.

Based on the results of serological and parasitological techniques (Carneiro et al. 2012, Pinheiro et al. 2012), 56 stool samples were selected from individuals aged between four-72 years, with a mean age of 30.49 years [standard deviation (SD) 17.78] and a median age of 26 years. This sample was divided into the following five groups for PCR analysis: Group I - Ten stool samples from individuals with reactive ELISA results, but without parasitological confirmation of S. mansoni eggs by KK. These stool samples were also negative for other parasitic diseases; Group II - Ten stool samples from individuals with reactive ELISA results, but without parasitological confirmation of S. mansoni eggs by KK. These stool samples were also positive for other parasitic diseases [Hookworm (5), Trichuris trichiura (5), Strongyloides stercoralis (2) and Taenia spp (1)]; Group III Seven stool samples from individuals with non-reactive ELISA results and without parasitological confirmation of $S$. mansoni eggs by KK. These stool samples were also positive for other parasitic diseases [Hookworm (1), T. trichiura (1), S. stercoralis (1), Entamoeba coli (2), Entamoeba histolytica/Entamoeba dispar complex (3), Ascaris lumbricoides (1) and Enterobius vermicularis (1)]; Group IV - Ten stool samples from individuals with non-reactive ELISA results, negative results for S. mansoni eggs by KK and negative stool tests for other parasitic diseases; Group V - Nineteen stool samples from individuals with reactive ELISA results and who tested positive for the presence of $S$. mansoni eggs by parasitological examination. Stool samples from Group V in sufficient amounts were also tested using two additional parasitological methods: the saline gradient method $(n=$ 17) and Helmintex ${ }^{\circledR}(\mathrm{n}=13)$.

Parasitological methods - The KK Kit [Bio-Manguinhos, Oswaldo Cruz Foundation, Rio de Janeiro (RJ), Brazil] was used according to the manufacturer's specifications and the saline gradient and Helmintex ${ }^{\circledR}$ methods were performed as described in previous studies (Pinheiro et al. 2012). One stool sample was collected from each individual and the KK exams were performed by analysing three slides per sample. For the identification of parasites other than $S$. mansoni, the Hoffman method (Hoffman et al. 1934) was used.

Serological assay for S. mansoni antibody detection (IgG ELISA) - Serum samples were tested using an immunoenzymatic reaction to measure the levels of $\operatorname{IgG}$ antibodies specific to $S$. mansoni, according to the protocol described by Colley et al. (1977), with a few modifications. A total extract from $S$. mansoni adult worms $(5 \mu \mathrm{g} / \mathrm{mL}$ ) was used as the antigen (provided by Prof Dr Alfredo Góes, Institute of Biological Sciences, Federal University of Minas Gerais). Peroxidase-labelled sheep anti-human immunoglobulin G antibody (1:1500) (Sigma-Aldrich, St. Louis, MO, USA) was used as the conjugate and ortho-phenylenediamine $(1 \mathrm{mg} / \mathrm{mL})$ with $\mathrm{H}_{2} \mathrm{O}_{2}$ 
$(0.1 \mathrm{~mL} / \mathrm{mL}$ ) in $0.2 \mathrm{M}$ citrate buffer ( $\mathrm{pH} 5.0$ ) was used as the substrate developer. All reactions were performed in a final volume of $100 \mu \mathrm{L}$. The cut-off value was determined to be 2 SD greater than the mean optical density value derived from 35 negative control samples tested on the same day as the experimental samples; these samples were obtained from apparently healthy individuals with no detectable parasitic diseases living outside of S. mansoni endemic areas.

DNA detection using PCR analyses - Control stool samples - DNA was extracted from S. mansoni eggs and from two stool samples from individuals with proven parasitic infections from an endemic area in RJ, which were used as positive controls. One stool sample had greater than $400 \mathrm{eggs} / \mathrm{g}$ and the other had fewer than $100 \mathrm{eggs} / \mathrm{g}$. In addition, 10 samples obtained from individuals living in non-endemic areas were used as negative controls.

DNA extraction - Total DNA was extracted from $300 \mu \mathrm{L}$ of each stool sample using the FastDNA Spin Kit (MP Biomedicals, Vista, CA, USA), according to the manufacturer's instructions. Eggs were disrupted using the FP120 Fast Prep Cell Disrupter (MP Biomedicals) for $10 \mathrm{sec}$ at a speed of $5.5 \mathrm{~ms}^{-1}$. The DNA was then purified using the QIAquick PCR Purification Kit (QIAGEN, Hilden, Germany) and was stored at $-20^{\circ} \mathrm{C}$.

$P C R$ - The following PCR parameters were used, according to the protocol described by Pontes et al. (2002), with the exception that the reverse primer sequence was modified by one nucleotide to yield $100 \%$ homology to the $S$. mansoni genome (SMFPONTES: 5'GATCTGAATCCGACC CG-3' and SMRPER: 5'-TATTAACGCCCACGCTCTCG-3'). The oligonucleotide primer pairs were designed to be specific to a highly repetitive region of the S. mansoni genome described by Hamburger et al. (1991). The reactions were performed in a final volume of $50 \mu \mathrm{L}$ and included $48 \mu \mathrm{L}$ MasterMix [45 $\mu$ L SuperMix (Invitrogen, Carlsbad, CA, USA), $1 \mu \mathrm{L}$ forward primer $\mathrm{F}(10 \mu \mathrm{M}), 1 \mu \mathrm{L}$ reverse primer $(10 \mu \mathrm{M}), 1 \mu \mathrm{L}$ magnesium chloride $(1.5 \mathrm{mM})]$ and $2 \mu \mathrm{L}$ purified DNA.

Template DNA was amplified using 35 cycles the following: a denaturation phase at $94^{\circ} \mathrm{C}$ for $30 \mathrm{sec}$, a hybridisation phase at $55^{\circ} \mathrm{C}$ for $30 \mathrm{sec}$ and an extension phase at $72^{\circ} \mathrm{C}$ for $30 \mathrm{sec}$, followed by a final extension phase at $72^{\circ} \mathrm{C}$ for $7 \mathrm{~min}$. A GeneAmp PCR System 2400 thermocycler (Applied BioSystems, CA, USA) was used. Amplified products (110 bp) were analysed using a photodocumentation system (Bio-Rad, Hercules, CA, USA) following electrophoresis through $2 \%$ agarose gels (Invitrogen) containing ethidium bromide.

Ethical considerations - The study was approved by the Ethical Review Board of the Faculty of Medicine of the Federal University of Ceará (165/09). Informed written consent was obtained from each study participant or, in the case of minors, from their legal guardians. In cases of $S$. mansoni infection, a single dose of praziquantel ( $60 \mathrm{mg} / \mathrm{kg}$ body weight) was administered. Participants with positive faecal examinations for intestinal helminths were treated with albendazole $(400 \mathrm{mg} / \mathrm{dose})$.

\section{RESULTS}

Stool and serum samples from 125 individuals were initially analysed using KK and ELISA tests. Only 5.6\% (7) of the individuals tested positive for the presence of S. mansoni eggs in their faeces based on the KK tests. One sample was deemed positive for eggs based on one slide, one sample was deemed positive based on two slides and an additional five samples were deemed positive based on all three slides. Of the 125 serum samples, $64 \%$ (80) were reactive in the $S$. mansoni ELISAs, including the seven KK-positive individuals. However, one of the KK-positive individuals did not provide a sufficient amount of stool for further parasitological examinations or PCR analysis.

When comparing the KK and PCR results from 56 S. mansoni-positive stool samples, we found that the KK method correctly identified positive samples in six $(10.7 \%)$ cases and that PCR correctly identified positive samples in $21(37.5 \%)$ cases. Thirteen of the PCR-positive samples were from Group V and the other PCRpositive samples were as follows: four/10 from Group I, two/10 from Group II and one positive sample each from Groups III and IV. The samples from Groups II and III revealed the presence of other parasites and no correlations were observed between these groups and the groups without parasite infection that also had positive PCR results (Table I).

Considering the 19 Group V samples, which were proven positive for $S$. mansoni using parasitological methods other than KK, six/19 were also positive by KK, nine/17 were positive by saline gradient and $10 / 13$ were positive by Helmintex ${ }^{\circledR}$. PCR analysis detected the presence of parasite DNA in 13 of these 19 samples (68.4\%). When comparing the KK and PCR results for the 19 Group V samples, five were scored positive for the presence of $S$. mansoni by both methods, eight were positive only by PCR, one was positive only by KK and five were scored negative by both tests. The proportion correctly detected by PCR was significantly higher $(p=0.002)$ than the proportion detected by the KK method (Table II).

Both the saline gradient method and PCR were performed on 17 samples in Group V. Seven samples were scored positive by both assays, four were positive only by PCR and two were positive only by the saline gradient method. There was no statistically significant difference between these methods $(p=0.688)$ (Table III).

The Helmintex ${ }^{\circledR}$ method and PCR were performed on 13 samples in Group V. Seven samples were scored positive by both assays, three were positive only by Helminte ${ }^{\circledR}$ and one was positive only by PCR. The proportion of samples correctly detected by PCR was statistically similar $(\mathrm{p}=0.125)$ to the proportion detected by Helmintex $^{\circledR}$ (Table IV).

The relationships between the results of the three parasitological tests and the PCR-based analysis are presented in Table V.

To verify the presence of inhibitory substances in the amplification reactions, all six stool samples from individuals without $S$. mansoni eggs and who tested negative by PCR were contaminated with $5 \mathrm{fg} S$. mansoni 
DNA. Amplification was not observed in two of these six samples, suggesting the presence of reaction inhibitors in these samples.

\section{DISCUSSION}

In this study, we examined the efficacy of a PCRbased method to diagnose the presence of $S$. mansoni eggs in the stool samples of individuals with low-intensity infections. To adequately monitor and control schistosomiasis, more accurate diagnostic methods are needed, which is especially pressing due to the high prevalence and incidence of this disease in some regions (Melo 2006). The control of schistosomiasis is now possible due to the development of a single-dose oral medication that can be easily administered to infected patients. Indeed, the treatment of entire communities can decrease morbidity and reduce egg excretion, although certain individuals will usually remain infected. Despite experimental data suggesting that praziquantel resistance can arise, there is currently no clinical evidence for this phenomenon (Doenhoff et al. 2008, Greenberg 2013). The most reasonable explanation for positive exams following treatment is re-infection due to living in an endemic area. Furthermore, the widespread impacts of chemicalbased and other treatment measures have been difficult to determine because the sensitivity of parasitological exams decreases dramatically when egg excretion is low or absent, particularly in areas of low transmission and/or endemicity. Therefore, more sensitive diagnostic methods are needed to combat schistosomiasis effectively (Gomes et al. 2010, Cavalcanti et al. 2013).

Relatively few studies have addressed the detection of $S$. mansoni DNA in clinical samples (Pontes et al. 2002, 2003, Sandoval et al. 2006, Oliveira et al. 2010). The usefulness of PCR for detecting $S$. mansoni DNA in human faecal samples was first described by Pontes et al. (2002). They demonstrated the detection of S. mansoni DNA in stool samples at 2.4 eggs per gram (EPG) of faeces, which indicated a 10 -fold greater sensitivity than KK examination; the detection limit was shown to be 1 fg of pure Schistosoma spp DNA.

A recent study by Gomes et al. (2010) assessed 206 individuals living in the town of Pedra Preta, state of Minas Gerais (MG), an endemic area for schistosomiasis. Using the KK technique, they determined an $S$. mansoni infection rate of $18 \%$ when examining 12 slides for each stool sample. In contrast, using a PCR-ELISA technique that was standardised for the detection of $S$. mansoni DNA, they determined a $30 \%$ infection rate. These results demonstrate that diagnostic sensitivity can be increased using this molecular technique.

In the present study, we analysed 56 samples and compared the results from a conventional PCR-based method with results from serological and parasitologi-

TABLE I

Results of Hoffman and polymerase chain reaction (PCR) methods from stool samples of Groups II and III

\begin{tabular}{|c|c|c|c|}
\hline Groups & Individuals & Hoffman & PCR \\
\hline \multirow[t]{10}{*}{ II } & $\mathrm{A} 1$ & $\begin{array}{l}\text { Strongyloides stercoralis } \\
\text { Trichuris trichiura }\end{array}$ & $\mathrm{N}$ \\
\hline & A2 & Ancylostoma $\mathrm{spp}$ & $\mathrm{N}$ \\
\hline & A3 & T. trichiura & $\mathrm{P}$ \\
\hline & A4 & Ancylostoma spp & $\mathrm{N}$ \\
\hline & A5 & T. trichiura & $\mathrm{P}$ \\
\hline & A6 & Ancylostoma spp & $\mathrm{N}$ \\
\hline & A7 & S. stercoralis & $\mathrm{N}$ \\
\hline & A8 & Taenia sp. & $\mathrm{N}$ \\
\hline & A9 & $\begin{array}{l}\text { Ancylostoma spp } \\
\text { T. trichiura }\end{array}$ & $\mathrm{N}$ \\
\hline & $\mathrm{A} 10$ & $\begin{array}{l}\text { Ancylostoma spp } \\
\text { T. trichiura }\end{array}$ & $\mathrm{N}$ \\
\hline \multirow[t]{7}{*}{ III } & $\mathrm{C} 1$ & S. stercoralis & $\mathrm{N}$ \\
\hline & $\mathrm{C} 2$ & Ancylostoma spp & $\mathrm{N}$ \\
\hline & $\mathrm{C} 3$ & $\begin{array}{c}\text { T. trichiura, } \\
\text { Entamoeba histolytica/Entamoeba dispar, } \\
\text { Escherichia coli }\end{array}$ & $\mathrm{N}$ \\
\hline & $\mathrm{C} 4$ & Enterobius vermicularis & $\mathrm{N}$ \\
\hline & $\mathrm{C} 5$ & $\begin{array}{c}\text { E. coli } \\
\text { E. histolytica/dispar }\end{array}$ & $\mathrm{N}$ \\
\hline & C6 & Ascaris lumbricoides & $\mathrm{N}$ \\
\hline & $\mathrm{C} 7$ & E. histolytica/dispar & $\mathrm{P}$ \\
\hline
\end{tabular}

$\mathrm{N}$ : negative; P: positive. 
cal tests. Among the 19 samples comprising Group V, S. mansoni was detected by the KK technique (reading 3 slides) in $33.9 \%$ of cases. In contrast, the PCR-based method was able to correctly score the samples in $68.4 \%$ of cases - a more than two-fold increase in sensitivity. However, these results differ from those obtained by Pontes et al. (2003) in a study conducted in Comercinho,

\section{TABLE II}

Comparison between the reference method Kato-Katz (KK) and polymerase chain reaction (PCR) method for schistosomiasis detection

\begin{tabular}{|c|c|c|c|}
\hline \multirow[b]{2}{*}{ PCR } & \multicolumn{2}{|c|}{$\begin{array}{c}\mathrm{KK} \\
\mathrm{n}(\%)\end{array}$} & \multirow{2}{*}{$\begin{array}{l}\text { Total } \\
\text { n (\%) }\end{array}$} \\
\hline & $\mathrm{P}$ & $\mathrm{N}$ & \\
\hline $\mathrm{P}$ & 5 & 8 & $13(68.4)$ \\
\hline $\mathrm{N}$ & 1 & 5 & $6(31.6)$ \\
\hline Total & $6(31.6)$ & $13(68.4)$ & 19 (100) \\
\hline
\end{tabular}

$\mathrm{N}$ : negative; P: positive.

TABLE III

Comparison between the polymerase chain reaction (PCR) and saline gradient methods for schistosomiasis detection

\begin{tabular}{|c|c|c|c|}
\hline \multirow[b]{2}{*}{ PCR } & \multicolumn{2}{|c|}{$\begin{array}{c}\text { Saline gradient } \\
\mathrm{n}(\%)\end{array}$} & \multirow{2}{*}{$\begin{array}{l}\text { Total } \\
\mathrm{n}(\%)\end{array}$} \\
\hline & $\mathrm{P}$ & $\mathrm{N}$ & \\
\hline $\mathrm{P}$ & 7 & 4 & $11(64.7)$ \\
\hline $\mathrm{N}$ & 2 & 4 & $6(35.3)$ \\
\hline Total & $9(52.9)$ & $8(47.1)$ & $17(100)$ \\
\hline
\end{tabular}

$\mathrm{N}$ : negative; P: positive.

TABLE IV

Comparison between the polymerase chain reaction (PCR) and Helmintex ${ }^{\circledR}$ methods for schistosomiasis detection

\begin{tabular}{|c|c|c|c|}
\hline \multirow[b]{2}{*}{ PCR } & \multicolumn{2}{|c|}{$\begin{array}{l}\text { Helmintex }^{\circledR} \\
\mathrm{n}(\%)\end{array}$} & \multirow{2}{*}{$\begin{array}{l}\text { Total } \\
\mathrm{n}(\%)\end{array}$} \\
\hline & $\mathrm{P}$ & $\mathrm{N}$ & \\
\hline $\mathrm{P}$ & 7 & 1 & $8(61.5)$ \\
\hline $\mathrm{N}$ & 3 & 2 & $5(38.5)$ \\
\hline Total & $10(76.9)$ & $3(23.1)$ & $13(100)$ \\
\hline
\end{tabular}

$\mathrm{N}$ : negative; P: positive.
MG. In that study, the authors reported a smaller difference between the results of parasitological examination and their PCR-based technique $(30.9 \%$ and $38.1 \%$, respectively), detecting only a 0.8 -fold increase in sensitivity using PCR. This discrepancy may be explained by the use of three stool samples in the parasitological analysis or because the study was performed in a highly endemic area for S. mansoni.

Of the 17 serum samples in negative control groups (Groups III and IV), PCR yielded two false positives. The presence of other parasites did not influence this result, as the number of PCR-positive samples in Group III (with other parasites) was similar to the number detected in Group IV (no other parasites). Although the potential for sample or reaction contamination did exist, the experiments were all conducted in duplicate and all conditions were properly controlled to minimise the possibility of contamination. When analysing the results from Groups II and III (with other parasites), we did not observe any relationships between the parasite species that were present and the results of the PCR analyses (Table I). In particular, only three samples were scored positive by PCR, two of which had T. trichiura and one of which had an E. histolytica/dispar complex. Indeed, these results may suggest past $S$. mansoni infections, as molecular techniques have been shown to display

\section{TABLE V}

Results of Kato-Katz (KK), saline gradient, Helmintex ${ }^{\circledR}$ and polymerase chain reaction (PCR) methods from stool samples of Group $\mathrm{V}$ for the presence of Schistosoma mansoni

\begin{tabular}{|c|c|c|c|c|}
\hline \multirow[b]{2}{*}{ Individuals } & \multicolumn{3}{|c|}{$\begin{array}{l}\text { Parasitological methods } \\
\text { (EPG) }\end{array}$} & \multirow[b]{2}{*}{$\mathrm{PCR}$} \\
\hline & KK & Saline gradient & Helmintex $^{\circledR}$ & \\
\hline E1 & $\mathrm{N}$ & $\mathrm{P}(10.0)$ & $\mathrm{N}$ & $\mathrm{P}$ \\
\hline E2 & $\mathrm{N}$ & $\mathrm{N}$ & $\mathrm{P}(0.10)$ & $\mathrm{N}$ \\
\hline E3 & $\mathrm{N}$ & $\mathrm{P}(2.0)$ & $\mathrm{P}(0.13)$ & $\mathrm{P}$ \\
\hline E4 & $\mathrm{N}$ & $\mathrm{N}$ & $\mathrm{P}(0.17)$ & $\mathrm{P}$ \\
\hline E5 & $\mathrm{P}(8.0)$ & $\mathrm{P}(10.0)$ & $\mathrm{P}(0.47)$ & $\mathrm{P}$ \\
\hline E6 & $\mathrm{N}$ & $\mathrm{P}(6.0)$ & $\mathrm{P}(0.13)$ & $\mathrm{P}$ \\
\hline E7 & $\mathrm{P}(8.0)$ & NR & $\mathrm{P}(4.77)$ & $\mathrm{P}$ \\
\hline E8 & $\mathrm{N}$ & $\mathrm{P}(2.0)$ & $\mathrm{N}$ & $\mathrm{N}$ \\
\hline E9 & $\mathrm{N}$ & $\mathrm{P}(6.0)$ & NB & $\mathrm{P}$ \\
\hline E10 & $\mathrm{N}$ & $\mathrm{P}(2.0)$ & NB & $\mathrm{P}$ \\
\hline E11 & $\mathrm{P}(8.0)$ & NR & NB & $\mathrm{P}$ \\
\hline E12 & $\mathrm{P}(8.0)$ & $\mathrm{N}$ & NB & $\mathrm{P}$ \\
\hline E13 & $\mathrm{N}$ & $\mathrm{N}$ & $\mathrm{P}(0.20)$ & $\mathrm{P}$ \\
\hline E14 & $\mathrm{P}(8.0)$ & $\mathrm{N}$ & $\mathrm{N}$ & $\mathrm{N}$ \\
\hline E15 & $\mathrm{N}$ & $\mathrm{P}(2.0)$ & NB & $\mathrm{N}$ \\
\hline E16 & $\mathrm{P}(8.0)$ & $\mathrm{N}$ & $\mathrm{P}(0.20)$ & $\mathrm{P}$ \\
\hline E17 & $\mathrm{N}$ & $\mathrm{N}$ & $\mathrm{P}(0.20)$ & $\mathrm{N}$ \\
\hline E18 & $\mathrm{N}$ & $\mathrm{P}(2.0)$ & NB & $\mathrm{P}$ \\
\hline E19 & $\mathrm{N}$ & $\mathrm{N}$ & $\mathrm{P}(0.30)$ & $\mathrm{N}$ \\
\hline
\end{tabular}

EPG: eggs per gram; N: negative; NR: not realised; P: positive. 
higher sensitivity when samples are collected from individuals living in endemic areas (Gomes et al. 2010, Oliveira et al. 2010).

In a study conducted among schoolchildren in Egypt by Allam et al. (2009), the researchers sought to demonstrate decreased detection of schistosomiasis in lowendemicity areas. The authors showed that $S$. mansoni eggs were detected by the Percoll technique in $11 \%$ of individuals who were scored negative by the KK technique (Dalton et al. 1997) and they also showed that the PCR technique could detect S. mansoni DNA in $23 \%$ of the KK-negative individuals. Interestingly, although all of the KK-positive cases were also scored positive by the Percoll method, the PCR technique yielded several negative results among the cases deemed positive by the parasitological methods.

Oliveira et al. (2010) performed another study that included stool samples from individuals in the low-endemicity area of Paracambi, RJ. The authors demonstrated that of 16 samples from a group of individuals with parasite loads less than 10 EPG of faeces, PCR yielded positive results in nine of these cases (56\%); this study used the same primer pair as in our study. In our study, 13 samples were scored positive by PCR among the 19 Group V samples, yielding a detection rate of $68.4 \%$.

Among the 39 ELISA-reactive samples, 19 were scored positive by PCR. In other words, using a molecular technique, we measured the presence of parasite DNA - indicating active infection - in $48.7 \%$ of the seropositive samples. Indeed, ELISA techniques using egg extracts as antigen have been shown to display crossreactivity when performed in endemic areas (de Noya et al. 2007, Grenfell et al. 2013), which could explain the results for the 14/20 (Groups I and II) ELISA-positive samples from individuals who did not test positive for $S$. mansoni infection by parasitological detection or PCR. Another possibility is that the ELISA technique can detect circulating antibodies from past infections in individuals who do not currently have eggs in their faeces.

PCR failed to detect DNA in six samples that were confirmed to be positive by parasitological examination and ELISA. Of these, only one sample was scored positive by the KK method (8 EPG) and two were scored positive by the saline gradient method (2 EPG); the other three samples were only scored positive by the Helmintex $^{\circledR}$ assay $(0.10,0.20$ and $0.30 \mathrm{EPG})$. Material from these six samples was tested for the presence of PCR inhibitors, which was indeed present in two of the six samples that were analysed. It is possible that in the other four samples, the quantity of stool used may not have contained the minimum number of parasite eggs required to obtain DNA during the extraction step, perhaps because the samples were taken from individuals from low-endemicity areas that had low parasite loads. It is also possible that variations in egg production and consequent uneven egg distribution within the faeces may have affected the results. Uneven egg distributions are typically minimised through faecal homogenisation; however, the quantity removed from the sample for parasitological examination may have removed the few eggs present in the sample.
The inhibition of Taq polymerase by certain substances found in clinical samples is already widely known and it presents a serious problem for the sensitivity of PCR-based methods. DNA extraction methods that minimise this effect have been described and have improved the efficiency of these techniques. Changes to PCR protocols and the inclusion of certain substances in DNA solutions, such as bovine serum albumin, have also minimised these effects. However, in some samples, the amounts or types of inhibitors present continue to interfere with PCR assays, compromising the sensitivity of the methods. Indeed, some laboratories have introduced structural modifications into Taq polymerase to make it more resistant to inhibitors, which may be helpful in these types of studies.

The use of PCR-based methods for detecting Schistosoma spp DNA in epidemiological surveys has also been limited because DNA extraction and PCR amplification can be relatively cumbersome and expensive compared with other methods. However, advances in DNA isolation and PCR techniques now make such assays a viable alternative (Verweij et al. 2004). Based on the literature, PCR appears to be an extraordinarily sensitive and specific tool for diagnosing schistosomiasis and it can be used to detect DNA in samples from individuals with as little as 2.4 EPG in their faecal matter (Hamburger et al. 1991). Furthermore, when the objective is disease control, the cost of a molecular technique should be weighed against the benefits obtained, which may be quite significant. Although none of the methods exhibited $100 \%$ sensitivity, PCR in combination with Helmintex ${ }^{\circledR}$ detected the presence of $S$. mansoni in 11 of the 13 samples we analysed. Based on these results, we conclude that of the use of two or more diagnostic tests in combination may be necessary for accurate diagnosis of this disease.

\section{ACKNOWLEDGEMENTS}

To the Health Secretariat of Maranguape and Health Secretariat of the State of Ceará, for their cooperation in the study.

\section{REFERENCES}

Allam AF, Kader O, Zaki A, Shehab AY, Farag F 2009. Assessing the marginal error in and PCR tecnics. Trop Med Int Health 14: 316-321.

Bergquist R, Johansen MV, Utzinger J 2009. Diagnostic dilemmas in helminthology: what tools to use and when? Trends Parasitol 25: $151-156$.

Carneiro TR, Pinheiro MC, de Oliveira SM, Hanemann AL, Queiroz JA, Bezerra FS 2012. Increased detection of schistosomiasis with Kato-Katz and SWAP-IgG-ELISA in a northeastern Brazil lowintensity transmission area. Rev Soc Bras Med Trop 45: 510-513.

Cavalcanti MG, Silva LF, Peralta RH, Barreto MG, Peralta JM 2013. Schistosomiasis in areas of low endemicity: a new era in diagnosis. Trends Parasitol 29: 75-82.

Coelho PMZ, Jurberg AD, Oliveira AA, Katz N 2009. Use of a saline gradient for the diagnosis of schistosomiasis. Mem Inst Oswaldo Cruz 104: 720-723.

Colley DG, Binder S, Campbell C, King CH, Tchuente LT, N'Goran EK, Erko B, Karanja DMS, Kabatereine NB, van Lieshout L, Rathbun S 2013. A five-country evaluation of a point-of-care circulating cathodic antigen urine assay for the prevalence of Schistosoma mansoni. Am J Trop Med Hyg 88: 426-432. 
Colley DG, Hieny SE, Bartholomew RK, Cook JA 1977. Immune response during human Schistosomiasis mansoni. III. Regulatory effect of patient sera on human lymphocytes blastogenic responses to schistosomal antigen preparations. Am J Trop Med Hyg 26: 917-922.

Coulibaly JT, Knopp S, N'Guessan NA, Silué KD, Fürst T, Lohourignon LK, Brou JK, N'Gbesso YK, Vounatsou P, N'Goran EK, Utzinger J 2011. Accuracy of urine circulating cathodic antigen (CCA) test for Schistosoma mansoni diagnosis in different settings of côte d'Ivoire. PLoS Negl Trop Dis 5: e1384.

Coulibaly JT, N'Gbesso YK, Knopp S, N'Guessan NA, Silué KD, van Dam GJ, N'Goran EK, Utzinger J 2013. Accuracy of urine circulating cathodic antigen test for the diagnosis of Schistosoma mansoni in preschool-aged children before and after treatment. PLoS Negl Trop Dis 7: e2109.

Dalton JP, Day SR, Drew AC, Brindley PJ 1997. A method for the isolation of schistosome eggs and miracidia free of contamination host tissues. Parasitology 115: 29-32.

de Noya BA, Ruiz-Guevara R, Colmenares C, Losada S, Noya O 2006. Low transmission areas of schistosomiasis in Venezuela: consequences on the diagnosis, treatment, and control. Mem Inst Oswaldo Cruz 101 (Suppl. I): 29-35.

de Noya BA, Ruiz-Guevara R, Losada S, Colmenares C, Contreras R, Cesari IM, Noya O 2007. Detection of schistosomiasis cases in low-transmission areas based on coprologic and serologic criteria: the Venezuelan experience. Acta Trop 103: 41-49.

Deelder A, de Jonge N, Boerman OC, Fillie YE, Hilberath GW, Rotmans JP, Gerritse MJ, Schut DWO 1989. Sensitive determination of circulating anodic antigen in Schistosoma mansoni infected individuals by an enzyme-linked immunosorbent assay using monoclonal antibodies. Am J Trop Med Hyg 40: 268-272.

Doenhoff MJ, Cioli D, Utzinger J 2008. Praziquantel: mechanisms of action, resistance and new derivatives for schistosomiasis. Curr Opin Infect Dis 21: 659-667.

Enk MJ, Lima AC, Drummond SC, Schall VT, Coelho PM 2008. The effect of the number of stool samples on the observed prevalence and the infection intensity with Schistosoma mansoni among a population in an area of low transmission. Acta Trop 108: 222-228.

Enk MJ, Silva GO, Rodrigues NB 2012. Diagnostic accuracy and applicability of a PCR system for the detection of Schistosoma mansoni DNA in human urine samples from an endemic area. PLoS ONE 7: e38947.

Espirito-Santo MCC, Alvarado-Mora MV, Pinto PLS, Carrilho FJ, Pinho JRR, Gryschek RCB 2012. Two sequential PCR amplifications for detection of Schistosoma mansoni in stool samples with low parasite load. Rev Inst Med Trop 54: 5.

Gentile R, Gonçalves MML, Neto SFC, Costa MM, Peralta RHS, Peralta JM 2011. Evaluation of immunological, parasitological and molecular methods for the diagnosis of Schistosoma mansoni infection before and after chemotherapy treatment with praziquantel in experimentally infected Nectomys squamipes. Vet Parasitol 180: $243-249$.

Gomes LI, Marques LHS, Enk MJ, Oliveira MC, Coelho PMZ, Rabello A 2010. Development and evaluation of a sensitive PCRELISA system for detection of Schistosoma infection in feces. PLoS Negl Trop Dis 4: e664.

Gonçalves MM, Barreto MG, Peralta RH, Gargioni C, Gonçalves T, Igreja RP, Soares MS, Peralta JM 2006. Immunoassays as an auxiliary tool for the serodiagnosis of Schistosoma mansoni infection in individuals with low intensity of egg elimination. Acta Trop 100: 24-30.
Greenberg RM 2013. New approaches for understanding mechanisms of drug resistance in schistosomes. Parasitology 3: 1-13.

Grenfell RFQ, Martins W, Enk M, Almeida A, Siqueira L, Silva-Moraes V, Oliveira E, Carneiro NFF, Coelho PMZ 2013. Schistosoma mansoni in a low-prevalence area in Brazil: the importance of additional methods for the diagnosis of hard-to-detect individual carriers by low-cost immunological assays. Mem Inst Oswaldo Cruz 108: 328-334.

Haggag SH, Abdullah SM 2011. Molecular diagnosis of Schistosoma mansoni infection in human serum and feces by using polymerase chain reaction. Life Sci J 8: 398-404.

Hamburger J, Turetski T, Kapeller I, Deresiewicz R 1991. Highly repeated short DNA sequences in the genome of Schistosoma mansoni recognized by a species-specific probe. Mol Biochem Parasitol 44: 73-80.

Hoffman WA, Pons JA, Janer JL 1934. Sedimentation concentration method in Schistosomiasis mansoni. Puerto Rico Journal of Public Health and Trop Medicine 9: 283-298.

Hotez PJ, Molyneux DH, Fenwick A, Ottesen E, Sachs SE, Sachs JD 2006. Incorporating a rapid-impact package for neglected tropical diseases with programs for HIV/AIDS, tuberculosis and malaria. PLoS Med 3: e102.

Kato-Hayashi N, Kirinoki M, Iwamura Y, Kanazaw T, Kitikoon V, Matsuda H 2010. Identification and differentiation of human schistosomes by polymerase chain reaction. Exp Parasitol 124: 325-329.

Katz N, Chaves A, Pellegrino JP 1972. A simple device for quantitative stool thick-smear in Schistosoma mansoni. Rev Inst Med Trop Sao Paulo 14: 397-400.

Legesse M, Erko B 2007. Field-based evaluation of a reagent strip test for diagnosis of Schistosoma mansoni by detecting circulating cathodic antigen in urine before and after chemotherapy. Trans $R$ Soc Trop Med Hyg 101: 668-673.

Melo FP 2006. Desenvolvimento de métodos moleculares baseados em PCR para a detecção de Schistosoma mansoni, MsD Thesis, Universidade Federal de Pernambuco, Recife, 114 pp.

Molyneux DH, Hotez PJ, Fenwick A 2005. "Rapid-impact interventions": how a policy of integrated control for Africa's neglected tropical diseases could benefit the poor. PLoS Med 2: 1064-1070.

Oliveira LMA, Santos HLC, Gonçalves MML, Barreto MGM, Peralta JM 2010. Evaluation of polymerase chain reaction as an additional tool for the diagnosis of low-intensity Schistosoma mansoni infection. Diagn Microbiol Infect Dis 68: 416-421.

Pinheiro MCC, Carneiro TR, Hanemann ALP, de Oliveira SM, Bezerra FSM 2012. The combination of three faecal parasitological methods to improve the diagnosis of schistosomiasis mansoni in a low endemic setting in the state of Ceará, Brazil. Mem Inst Oswaldo Cruz 107: 873-876.

Pontes LA, Dias-Neto E, Rabello A 2002. Detection by polymerase chain reaction of Schistosoma mansoni DNA in human serum and feces. Am J Trop Med Hyg 66: 157-162.

Pontes LA, Oliveira MC, Katz N, Dias-Neto E, Rabello A 2003. Comparison of a polymerase chain reaction and the Kato-Katz technique for diagnosing infection with Schistosoma mansoni. Am J Trop Med Hyg 68: 652-656.

Sandoval N, Siles-Lucas M, Perez-Arellano JL, Carranza C, Puente S, Lopez-Aban J, Muro A 2006. A new PCR-based approach for the specific amplification of DNA from different Schistosoma species applicable to human urine samples. Parasitology 133: 581-587.

Steinmann P, Keiser J, Bos R, Tanner M, Utzinger J 2006. Schistosomiasis and water resources development: systematic review, 
meta-analysis and estimates of people at risk. Lancet Infect Dis 6: $411-425$

Stothard JR, Sousa-Figuereido JC, Betson M, Adriko M, Arinaitwe M, Rowell C, Besiyge F, Kabatereine NB 2011. Schistosoma mansoni infections in young children: when are schistosome antigens in urine, eggs in stool and antibodies to eggs first detectable? PLoS Negl Trop Dis 5: e938.

Sulbaran GS, Ballen DE, Bermudez H, Lorenzo M, Noya O, Cesari IM 2010. Detection of the Sm31 antigen in sera of Schistosoma mansoni infected patients from a low endemic area. Parasite Immunol 32: 20-28.

Teixeira CF, Neuhauss E, Bem R, Romanzini J, Graeff-Teixeira C 2007. Detection of Schistosoma mansoni eggs in feces through their interaction with paramagnetic beads in a magnetic field. PLoS Negl Trop Dis 1: e73.

ten Hove RJ, Verweij JJ, Vereecken K, Polman K, Dieye L, van Lieshout L 2008. Multiplex real-time PCR for the detection and quantification of Schistosoma mansoni and S. haematobium infection in stool samples collected in northern Senegal. Trans $R$ Soc Trop Med Hyg 102: 179-185.

Utzinger J, Booth M, N'Goran EK, Muller I, Tanner M, Lengeler C 2001. Relative contribution of day-to-day and intra-specimen variation in faecal egg counts of Schistosoma mansoni before and after treatment with praziquantel. Parasitology 122: 532-544.

van der Werf MJ, de Vlas SJ, Brooker S, Looman CWN, Nagelkerke NJD, Habbema JDF, Engels D 2003. Quantification of clinical morbidity associated with schistosome infection in sub-Saharan Africa. Acta Trop 86: 125-139.

van Etten L, Folman CC, Eggelte TA, Kremsner PG, Deelder AM 1994. Rapid diagnosis of schistosomiasis by antigen detection in urine with a reagent strip. J Clin Microbiol 32: 2404-2406.

van Lieshout L, de Jonge N, Mansour MM, Bassily S, Krijger FW, Deelder AM 1993. Circulating cathodic antigen levels in serum and urine of schistosomiasis patients before and after chemotherapy with praziquantel. Trans $R$ Soc Trop Med Hyg 87: 311-312.

Verweij JJ, Blange RA, Templeton K, Schinkel J, Brienen EA, van Rooyen MA, van Lieshout L, Polderman AM 2004. Simultaneous detection of Entamoeba histolytica, Giardia lamblia and Cryptosporidium parvum in fecal samples using multiplex real-time PCR. J Clin Microbiol 3: 1220-1223.

Wichmann D, Panning M, Quack T, Kramme S, Burchard GD, Grevelding C, Drosten C 2009. Diagnosing schistosomiasis by detection of cell-free parasite DNA in human plasma. PLoS Negl Trop Dis 3: e422. 